\title{
Assessment of Liver Fatty Acid Binding Protein (L-FABP) as a Diagnostic Marker in Non-Alcoholic Fatty Liver Disease
}

\author{
Badawy A. Abdulaziz ${ }^{*}$, Sabry Anis Abdu', Ahmed Mostafa Amin², \\ Ahmed Khayri Abdel Hamid El Menyawi ${ }^{3}$, Abdelmoneam Ahmed ${ }^{4}$, Medhat A. Khalil', \\ Walid A. Abdel Halim 5
}

\author{
${ }^{1}$ Hepatology, Gastroenterology and Infectious Diseases Department, Faculty of Medicine, Benha University, Benha, Egypt \\ ${ }^{2}$ Medical Microbiology and Immunology, Tanta Faculty of Medicine, Tanta University, Tanta, Egypt \\ ${ }^{3}$ KafrElsheikh Hospital Internal Medicine, Kafr El Sheikh, Egypt \\ ${ }^{4}$ Internal Medicine Department, Faculty of Medicine, Benha University, Benha, Egypt \\ ${ }^{5}$ Department of Clinical and Chemical Pathology, Faculty of Medicine, Benha University, Benha, Egypt \\ Email: ^badawyabdelkhalek123@gmail.com, ^Badawi.omar@fmed.bu.edu.eg
}

How to cite this paper: Abdulaziz, B.A., Abdu, S.A., Amin, A.M., El Menyawi, A.K.A.H., Ahmed, A., Khalil, M.A. and Halim, W.A.A. (2019) Assessment of Liver Fatty Acid Binding Protein (L-FABP) as a Diagnostic Marker in Non-Alcoholic Fatty Liver Disease. Open Journal of Gastroenterology, 9, 113-124.

https://doi.org/10.4236/ojgas.2019.96014

Received: May 9, 2019

Accepted: June 25, 2019

Published: June 28, 2019

Copyright $\odot 2019$ by author(s) and Scientific Research Publishing Inc. This work is licensed under the Creative Commons Attribution International License (CC BY 4.0).

http://creativecommons.org/licenses/by/4.0/

\begin{abstract}
Background: Non-Alcoholic Fatty Liver Disease (NAFLD) is the most common liver disease worldwide, it causes chronic hepatitis, which leads to cirrhosis and hepatocellular carcinoma. We aimed to assess the value of liver fatty acid binding protein (L-FABP) in the diagnosis of non-alcoholic fatty liver disease in comparison to ultrasonography. Patients and Methods: Ninty subjects were enrolled in this study who attended the Hepatology, Gastroenterology and Internal medicine clinics in Benha University Hospitals between January 2017 and January 2018 and divided into group I included 70 consecutive patients with non-alcoholic fatty liver disease who were diagnosed by ultrasound with or without elevated liver enzymes and group $\Pi$ included 20 healthy control subjects without NAFLD (by ultrasound) with normal liver enzymes. Serum levels of L-FABP were determined by enzyme-linked immunosorbent assay. Results: NAFLD patients were slightly older than healthy subjects as mean age in group I was (37.74 \pm 11.7$)$ while in group $\Pi$ was (36.5 \pm 11.31 ). There was a slight increase in NAFLD in males, there was a high prevalence of NAFLD in the urban population. L-FABP levels in NAFLD patients were higher than in the control group (levels were $188.6 \pm 34.94$ and $137.7 \pm 13.05 \mathrm{ng} / \mathrm{l}$ respectively). A strong correlation was found between L-FABP and ALT, AST, BMI and glucose levels. Analysis of ROC curve revealed that at a level $151.1 \mathrm{ng} /$ sensitivity, specificity, PPV, NPV and accuracy were $83.3 \%, 71.8 \%, 31.3 \%, 96.6 \%$ and $73.3 \%$ respectively with AUC 0.839 and at a level $189.5 \mathrm{ng} /$ sensitivity, specificity, PPV, NPV and accuracy were 90\%,
\end{abstract}


90\%, 95.4\%, 95.4\%, 88.9\% with AUC was 0.950. Conclusion: Serum L-FABP could be used as a new diagnostic biomarker for detecting NAFLD.

\section{Keywords}

NAFLD, L-FABP, Chronic Hepatitis, Cirrhosis, Hepatocellular Carcinoma

\section{Introduction}

NAFLD is one of the most important causes of liver disease worldwide and will probably emerge as the leading cause of end-stage liver disease in the coming decade [1]. It encompasses a wide spectrum of histological and clinical manifestations, ranging from simple steatosis to steatohepatitis, fibrosis and cirrhosis [2].

The global prevalence of NAFLD is currently estimated to be 24 [3]. But the highest rates are reported from South America (31\%) and the Middle East (32\%), followed by Asia (27\%), the USA (24\%) and Europe (23\%), whereas NAFLD is less common in Africa (14\%) [3]. Fatty acid-binding proteins (FABPs) are a family of small and highly conserved lipid chaperone molecules with highly varied functions [1]. Different members of the FABP family exhibit unique patterns of tissue expression and are expressed most abundantly in tissues involved in active lipid metabolism in hepatocytes, adipocytes and cardiac myocytes, where fatty acids are prominent substrates for lipid biosynthesis, storage or breakdown, the respective FABPs make up between $1 \%$ and $5 \%$ of all soluble cytosolic proteins [4]. In the hepatic lobule, L-FABP is expressed in hepatocytes in a declining gradient from portal to central location [5]. In addition, epithelial cells of the proximal tubules in kidneys express L-FABP mRNA [6]. A previous study has shown L-FABP to be a promising biochemical marker for the early detection of hepatocellular injury in a small group of liver transplant patients [7]. It was reported that urinary excretions of L-FABP are increased in patients with chronic hepatitis [8]. Liver type FABP (L-FABP), significantly expressed in hepatocytes, enterocytes and to a lesser degree in renal tubular cells [9]. L-FABP is a protein involved in multiple biologic functions, such as intracellular fatty acid transport, cholesterol and phospholopid metabolism, which plays an important facilitative role in hepatic fatty acid oxidation [10].

\section{Material and Methods}

1) This observational case control study was conducted on 90 subjects attended the clinics of Hepatology, Gastroenterology and Infectious Diseases, and Internal medicine in Benha University Hospitals during the period from January 2017 to January 2018 and a written informed consent was obtained from all participants prior to recruitment and divided into group I included 70 consecutive patients with non-alcoholic fatty liver disease who were diagnosed by ultrasound 
with or without elevated liver enzymes and group II included 20 healthy control subjects without NAFLD (by ultrasound) with normal liver enzymes. Subjects with any amount of alcohol consumption or history of alcohol consumption, steatogenic medications (amiodarone, valproic acid, corticosteroids and tetracyclines).

2) HCV antibody positive, Hepatitis B surface antigen positive, chronic kidney disease, polycystic kidney disease, Other Causes of chronic liver disease other than HCV and HBsAg positive patients (by history and examination): hemochromatosis, Wilson disease, autoimmune hepatitis and drug abusers were excluded. Full history taking, clinical examination with stress on weight and height which measured in light clothing without shoes and body mass index (BMI) was calculated by dividing the weight by the square of the height $\left(\mathrm{kg} / \mathrm{m}^{2}\right)$ and laboratory tests including $\mathrm{CBC}$, blood sugar, ALT, AST, Serum creatinine, viral markers (HBsAg, anti-HCV Ab)were assayed using an enzyme immunoassay (EIA) Kit (Abbott, Axyam USA), lipid profile and serum liver fatty acid binding protein (L-FABP ng/L): L-FABP was measured with a sandwich enzyme-linked immunosorbent assay developed in collaboration with sunshine Biotechnology. The detection limit of the assay was $151.1 \mathrm{ng} / \mathrm{L}$.

\subsection{Assay Procedure for FABP}

Add L-FABP to a monoclonal antibody enzyme well which is precoated with human L-FABP monoclonal antibody, incubation; then, add (L-FABP) antibodies labeled with biotin, and combined with streptavidin-HRP to form immune complex; then carry out incubation and washing again to remove the uncombined enzyme. Then add chromogen solution A, B, the color of the liquid changes into blue, and at the effect of acid, the color finally becomes yellow. The chroma of color and the concentration of the human substance L-FABP of the sample were positively correlated.

Also, Ultrasonography TOSHIBA SSA-700A (Apilo 5) was performed to assess the liver condition including NAFLD according to [11]. as follows:

Grade 1: The echogenicity of the liver is just increased.

Grade 2: When the echogenic liver obscures the echogenic walls of portal vein branches.

Grade 3: When the echogenic liver obscures the diaphragmatic outline.

\subsection{Statistical Analysis}

The analysis of the data was carried out using SPSS (SPSS Inc., Chicago, ILL Company) 16 software. Categorical data were presented as number and percentages while quantitative data were expressed as mean \pm standard deviation Median, IQR and range. Fisher-exact test (FET) was used to analyze categorical variables. Quantitative data were tested for normality using Shapiro-Wilks test, assuming normality at $\mathrm{P}>0.05$. Student " $\mathrm{t}$ " test was used to analyze normally distributed variables among 2 independent groups. While non-parametric va- 
riables were analyzed using Man Whitney $\mathrm{U}$ test (Z MWU). Difference among 3 independent means was analyzed using ANOVA for parametric variables or Kruskal Wallis test (KW) for non-parametric ones. Significant ANOVA and KW tests were followed by post hoc multiple comparisons using Bonferroni tests to detect the significant pairs. Correlations between L-FABP and the studied variables were assessed by Spearman's correlation coefficient (rho). ROC curves were constructed to determine cutoff values of L-FABP in the prediction of fatty liver and its grades. The accepted level of significance in this work was stated at 0.05 ( $\mathrm{P}<0.05$ was considered significant).

$P$ value $>0.05$ is non-significant (NS)

$\mathrm{P}<0.05$ is significant $(\mathrm{S})$

$\mathrm{P} \leq 0.001$ is highly significant (HS)

Positive predictive value is the probability of patients with positive test results who are correctly diagnosed. Negative predictive value is the proportion of patients with negative test results who are correctly diagnosed.

\section{Results}

This study included 70 consecutive patients with NAFLD and 20 apparently healthy subjects. The epidemiologic characteristics and laboratory parameters of the two groups were summarized in Table 1. The mean age of NAFLD patients was $37.74 \pm 11.7$ years while in healthy control subjects was $36.5 \pm 11.31$ with no statistical significant difference between the two groups. There was female predominance among both groups with no statistical significance difference. Concerning the residence, either rural or urban, $64.29 \%$ of group (I) cases had urban residence in comparison with a group (П) which was $35 \%$ urban residence and this was statistically significant $(\mathrm{p}<0.01)$.

As regard BMI, there was a significant statistical difference between group I and group II concerning height, weight and BMI with mean value (171.5 \pm 8.3$)$, $(84.5 \pm 9.5),(28.76 \pm 4.3)$ in group I and (177.6 \pm 6.67$),(74.65 \pm 7.44),(23.72 \pm$ 3.04) in group II respectively (Table 1 ).

As regard biochemical and molecular parameters: There was a highly statistically significant difference between studied groups as regard total cholesterol, TG, HDL and LDL $(\mathrm{p}<0.001)$. Also there was a statistical significant difference between studied groups as regard AST, ALT and FBS ( $p<0.04, \mathrm{p}<0.03$ and $\mathrm{P}<0.03$ respectively). Also, there was a highly statistically significant difference between studied groups as regard L-FABP $(\mathrm{P}<0.001)$ that was increased in group I more than in group II (Table 1). There was increase in levels of L-FABP in serum of NAFLD patients in relation to grades of fatty liver by ultrasound as mean levels of L-FABP $(177.6 \pm 26.0)$ corresponds to grade I fatty liver, mean levels of $(189.4 \pm 29.2)$ corresponds to grade $\Pi$ fatty liver and mean levels of (220.5 \pm 48.5$)$ corresponds to grade $\amalg$ fatty liver and this was clinically and statistically significant $(\mathrm{p}<0.001)$ (Table 2 and Figure 1$)$. Also, there was a good positive correlation between grades of fatty liver by ultrasound and serum levels of L-FABP and this was statistically significant $(\mathrm{p}=0.002)$ (Table 3 and Figure 2). 
Table 1. Sociodemographic features of the studied groups.

\begin{tabular}{|c|c|c|c|c|}
\hline & $\begin{array}{c}\text { Group I } \\
n=70\end{array}$ & $\begin{array}{c}\text { Group } \Pi \\
n=20\end{array}$ & Test of sig. & $\mathrm{p}$ \\
\hline \multicolumn{5}{|l|}{ Sex } \\
\hline Male & $32(45.7)$ & $8(40 \%)$ & 0.206 & 0.650 \\
\hline Female & $38(54.3)$ & $12(60 \%)$ & & \\
\hline \multicolumn{5}{|l|}{ Residence } \\
\hline Urban & 45 (64.29) & $7(35 \%)$ & 5.46 & $<0.01$ \\
\hline Rural & $25(35.71)$ & $13(65 \%)$ & & \\
\hline $\mathrm{DM}$ & $15(21.4 \%)$ & $0(0 \%)$ & - & $<0.02$ \\
\hline \multicolumn{5}{|l|}{ Age } \\
\hline mean $\pm S D$ & $37.74 \pm 11.7$ & $36.5 \pm 11.31$ & 0.49 & 0.625 \\
\hline Hepatomegaly & $18(25.71 \%)$ & $1(5 \%)$ & 4.08 & $<0.04$ \\
\hline Splenomegally & $6(8.57 \%)$ & $2(10 \%)$ & 0.03 & 0.84 \\
\hline Height & $171.5 \pm 8.3$ & $177.6 \pm 6.67$ & 2.86 & $<0.01$ \\
\hline Weight & $84.5 \pm 9.5$ & $74.65 \pm 7.44$ & 4.26 & $<0.01$ \\
\hline BMI & $28.76 \pm 4.3$ & $23.72 \pm 3.04$ & 4.7 & $<0.01$ \\
\hline Total cholesterol & $220.09 \pm 22.01$ & $203.20 \pm 15.81$ & 3.22 & $<0.01$ \\
\hline TGs & $219.09 \pm 62.92$ & $173.50 \pm 29.43$ & 3.13 & $<0.01$ \\
\hline HDL & $40.61 \pm 7.49$ & $62.10 \pm 6.58$ & 11.59 & $<0.00$ \\
\hline LDL & $151.76 \pm 19.53$ & $120.50 \pm 21.49$ & 6.17 & $<0.00$ \\
\hline S. creatinine $(\mathrm{mg} / \mathrm{dl})$ & $0.97 \pm 0.23$ & $1.01 \pm 0.18$ & 0.71 & 0.47 \\
\hline Bilirubin (mg/dl) & $0.99 \pm 0.16$ & $0.956 \pm 0.16$ & 0.86 & 0.38 \\
\hline Salbumin (g/dl) & $3.73 \pm 0.22$ & $3.72 \pm 0.18$ & 0.17 & 0.86 \\
\hline INR & $1.17 \pm 0.14$ & $1.2 \pm 0.18$ & 0.78 & 0.43 \\
\hline AST (IU/L) & $36.7 \pm 13.46$ & $33.8 \pm 11.4$ & 2.08 & $<0.04$ \\
\hline $\operatorname{ALT}(\mathrm{IU} / \mathrm{L})$ & $40.31 \pm 14.94$ & $34.35 \pm 12.01$ & 2.21 & $<0.03$ \\
\hline $\operatorname{ALP}(U / L)$ & $38.2 \pm 13.28$ & $30.95 \pm 7.85$ & 2.32 & $<0.02$ \\
\hline FBS & $118.7 \pm$ & $96.8 \pm 11.9$ & 2.17 & $<0.03$ \\
\hline Serum L-FABP (ng/ml) & $188.6 \pm 34.94$ & $137.7 \pm 13.05$ & 6.11 & $<0.001$ \\
\hline
\end{tabular}

Table 2. Serum L-FABP level according to US grade of fatty liver.

\begin{tabular}{|c|c|c|c|c|c|c|}
\hline \multirow{2}{*}{ Group } & \multirow{2}{*}{ n. } & \multicolumn{3}{|c|}{ Serum L-FAB } & \multirow{2}{*}{$\begin{array}{c}\text { KW test a7 } \\
\mathbf{P}\end{array}$} & \multirow{2}{*}{ Sig pairs } \\
\hline & & Mean & $\pm \mathrm{SD}$ & Range & & \\
\hline Normal & 20 & 137.7 & 13.0 & $120-160$ & & $\mathrm{~N} \neq \mathrm{I}$ \\
\hline Grade I & 36 & 177.6 & 26.0 & $130-230$ & 45.08 & $\mathrm{~N} \neq \mathrm{II}$ \\
\hline Grade II & 22 & 189.4 & 29.2 & $148-261$ & $\begin{array}{c}\& \\
<0.001(\mathrm{HS})\end{array}$ & $\begin{array}{c}\mathrm{N} \neq \mathrm{III} \\
\mathrm{I} \neq \mathrm{III}\end{array}$ \\
\hline Grade III & 12 & 220.5 & 48.5 & $177-334$ & & $\mathrm{II} \neq \mathrm{III}$ \\
\hline
\end{tabular}

Table 3. Correlation between the grade of fatty liver and Serum L-FABP.

\begin{tabular}{ccc}
\hline \multirow{2}{*}{ With } & \multicolumn{2}{c}{ L.FABP } \\
\cline { 2 - 3 } & Rho & P \\
\hline Grade of fatty liver & 0.362 & $0.002(\mathrm{~S})$ \\
\hline
\end{tabular}




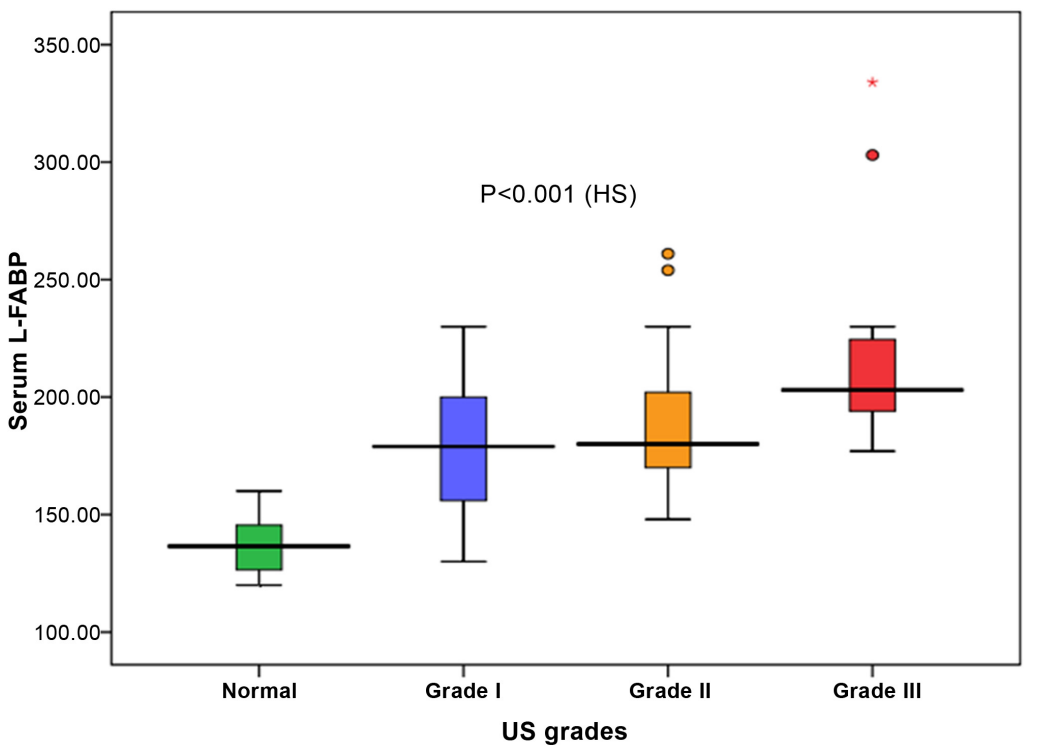

Figure 1. Box plot showing median and IQR of S. L-FABP according to US grades, with an increase of U/S grades of fatty liver there was an increase in s.L-FABPn and this was statisticaly significant $(\mathrm{p}<0.001)$.

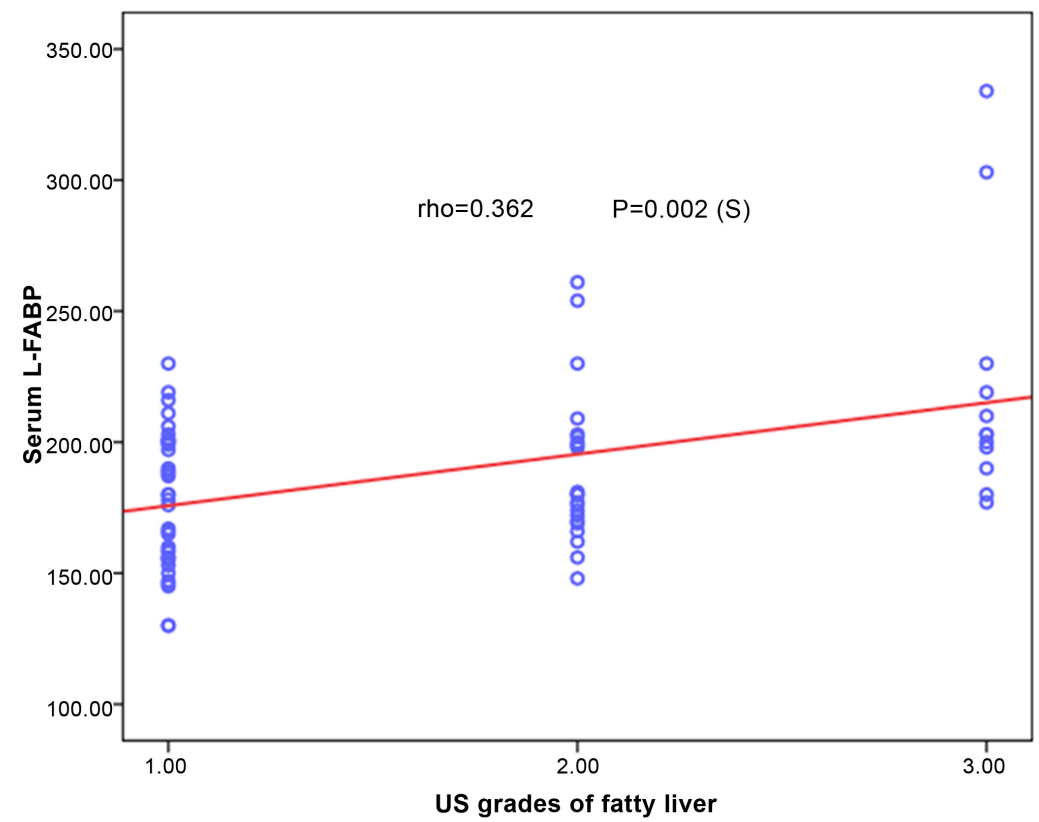

Figure 2. Scatter graph showing significant positive correlation between grades of fatty liver and L-FABP and this was statistically significant $(\mathrm{p}=0.002)$.

In the receiver operating curve (ROC), the area under curve (AUC) for L-FABP was 0.839 at a cutoff point $151.1 \mathrm{ng} / \mathrm{L}$ with sensitivity, specificity, Positive and negative predictive values were $83.3 \%, 71.8 \%, 31.3 \%$ and $96.6 \%$ respectively while at a cutoff point $189.5 \mathrm{ng} / \mathrm{L}$ the AUC was 0.950 with sensitivity, specificity, positive and negative predictive values were $90 \%, 85 \%, 95.4 \%$ and $70.8 \%$ respectively and this was highly statistically significant $(\mathrm{p}<0.001)$ (Table 4 and Figure $3 \&$ Figure 4). As regard the degree of agreement between U/S and serum 
Table 4. Shows the performance of Serum L-FABP in the prediction of Group I (fatty liver).

\begin{tabular}{ccccccccc}
\hline Score & Sens\% & Spec\% & PPV\% & NPV\% & Accuracy\% & AUC & $95 \%$ CI & P \\
\hline LFAB $\geq 151.1$ & $83.3 \%$ & $71.8 \%$ & $31.3 \%$ & $96.6 \%$ & $73.3 \%$ & 0.839 & $0.75-0.93<0.001$ (HS) \\
LFAB $\geq 189.5 \mathrm{ng} / \mathrm{L}$ & $90 \%$ & $85 \%$ & $95.4 \%$ & $70.8 \%$ & $88.9 \%$ & 0.950 & $0.91-0.99<0.001$ (HS) \\
\hline
\end{tabular}

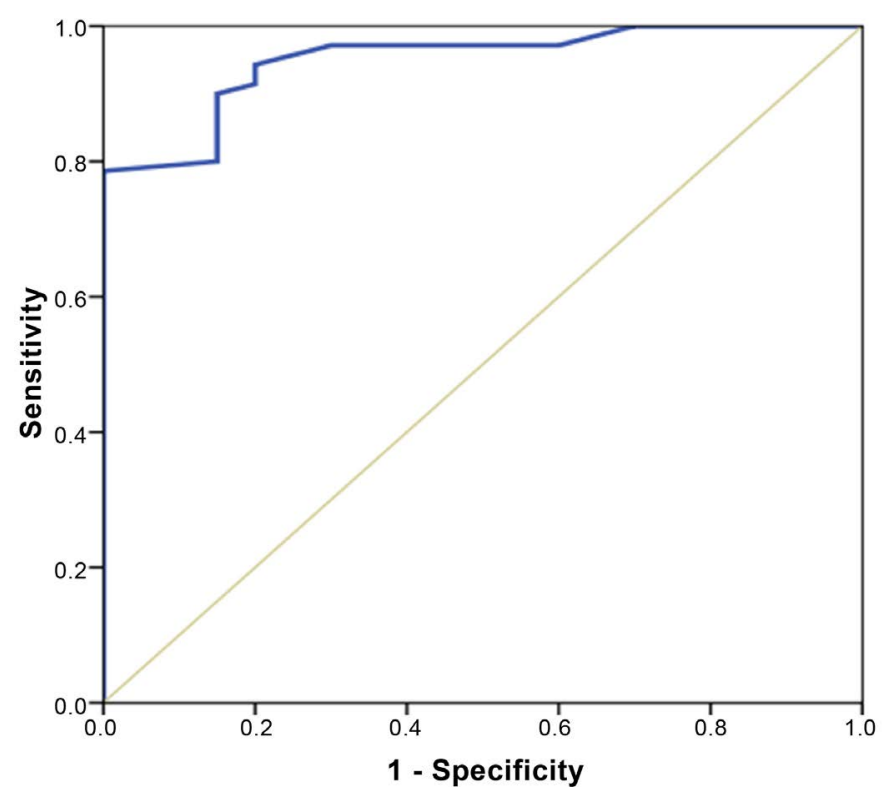

Figure 3. ROC curve for the performance of Serum L-FABP in the prediction of Group I (fatty liver) that at level $\geq 151.1$ sensitivity, specificity and AUC were $(83.3 \%, 71.8 \%$ and 0.839 respectively).

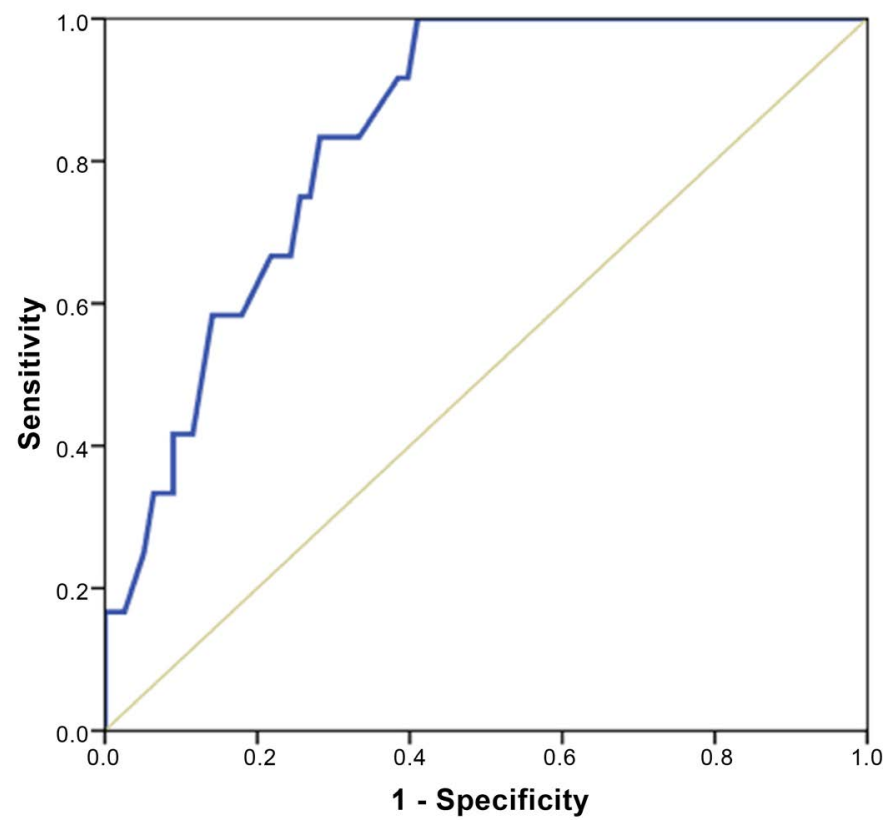

Figure 4. ROC curve for the performance of Serum L-FABP in the prediction of grade III fatty liver among Group I that at level $\geq 189.5$. sensitivity, specificity and AUC were (90\%, 85\% and 0.950 respectively). 
L-FAB in the detection of NAFLD, the degree of agreement was $88.9 \%$ (Cohen Kappa test $=0.70)$ and this was statistically significant $(\mathrm{p}<0.05)($ Table 5$)$. Also, the degree of agreement between U/S and serum L-FABP in the detection of grade III NAFLD was $72.8 \%$ (Cohen Kappa test $=0.461$ ) and this was statistically significant $(\mathrm{p}<0.05)$ (Table 6).

\section{Discussion}

NAFLD is one of the most prevalent causes of chronic liver disease worldwide [3]. And represents a spectrum of diseases with some patients developing cirrhosis and hepatocellular carcinoma (HCC)) [2]. A large number of patients with NAFLD with potential for progressive liver disease creates challenges for screening, as the diagnosis of NASH necessitates invasive liver biopsy [3]. L-FABP has a low molecular weight and is present in liver cells [7]. The properties of L-FABP lead to its elevation even with a small amount of cell injury. Since hepatocytes are in direct contact with the blood and have no interstitial barrier, small proteins appear sooner in the circulation than large proteins. For these reasons, L-FABP could be a promising biochemical marker for early detection of liver cell injury [7]. The aim of this study was to assess the diagnostic value of L-FABP in

Table 5. Degree of agreement between U/S and serum L-FAB in detection of NAFLD.

\begin{tabular}{|c|c|c|c|c|c|}
\hline & & & \multicolumn{2}{|c|}{ NAFLD by sonar } & \multirow{2}{*}{ Total } \\
\hline & & & Yes & No & \\
\hline \multirow{4}{*}{$\begin{array}{l}\text { NAFLD by marker } \\
(\geq 151.1)\end{array}$} & & Count & 63 & 3 & 66 \\
\hline & Yes & $\%$ & $90.0 \%$ & $15.0 \%$ & $73.3 \%$ \\
\hline & & Count & 7 & 17 & 24 \\
\hline & No & $\%$ & $10.0 \%$ & $85.0 \%$ & $26.7 \%$ \\
\hline \multirow{2}{*}{ Total } & & Count & 70 & 20 & 90 \\
\hline & & $\%$ & $100.0 \%$ & $100.0 \%$ & $100.0 \%$ \\
\hline
\end{tabular}

Cohen Kappa test $=0.70, \mathrm{P}<0.001$ (HS), Degree of agreement $=88.9 \%$.

Table 6. Degree of agreement between U/S and serum L-FABP in detection of grade III NAFLD.

\begin{tabular}{|c|c|c|c|c|c|}
\hline & & & \multicolumn{2}{|c|}{ NAFLD grade III by sonar } & \multirow{2}{*}{ Total } \\
\hline & & & Yes & No & \\
\hline \multirow{4}{*}{$\begin{array}{l}\text { NAFLD by marker } \\
(\geq 189.5)\end{array}$} & Yo & Count & 10 & 17 & 27 \\
\hline & $10 \mathrm{~s}$ & $\%$ within SonarIII & $83.3 \%$ & $29.3 \%$ & $38.6 \%$ \\
\hline & & Count & 2 & 41 & 43 \\
\hline & 10 & $\%$ within SonarIII & $16.7 \%$ & $70.7 \%$ & $61.4 \%$ \\
\hline \multirow{2}{*}{ Total } & & Count & 12 & 58 & 70 \\
\hline & & $\%$ within SonarIII & $100.0 \%$ & $100.0 \%$ & $100.0 \%$ \\
\hline
\end{tabular}

Cohen Kappa test $=0.461, \mathrm{P}<0.001$ (HS), Degree of agreement $=72.8 \%$. 
detection of NAFLD in comparison to ultrasound. In the current study, NAFLD patients were slightly older than healthy subjects as mean age in group I was $(37.74 \pm 11.7)$ while in group $\Pi$ was $(36.5 \pm 11.31)$, but this was statistically non-significant. In the present study, there was a slight increase of NAFLD in males $(\mathrm{n}=32,45.7 \%)$ in group $\mathrm{I}$ than group $\Pi(\mathrm{n}=8,40 \%)$. While females were $(\mathrm{n}=38,54.3 \%)$ in group I and $(\mathrm{n}=12,60 \%)$ in group $\Pi$. Sayiner et al., (2016) reported that several studies provide data to suggest a higher prevalence in males while others proposed the opposite [12]. In the current study, there was a high prevalence of NAFLD in urban population $(\mathrm{n}=45,64.29 \%)$ than rural ones ( $\mathrm{n}=$ 25, 35.71\%). This matches the study of Niriella et al., (2017) who reported that the urban cohort, when followed up for 7 years and subjected to ultrasonography of the liver again, showed their prevalence of NAFLD had increased dramatically to nearly $66 \%$ in that age ( $42-71$ years) population. The annual incidence of NAFLD in this population was $6.6 \%$ [13]. In the present study, there was a strong relationship between NAFLD and body mass index. BMI was elevated markedly in group I $(28.76 \pm 4.3)$ than group $\Pi(23.74 \pm 3.04)$. This matched the study of Williams et al., (2011) who stated that NAFLD is strongly linked to obesity, with a reported prevalence as high as $80 \%$ in obese patients and only $16 \%$ in individuals with a normal BMI and without metabolic risk factors [14]. In the current study serum triglycerides (219.09 \pm 62.92$)$, total cholesterol $(220.24 \pm 22.01)$ and LDL $(151.76 \pm 19.53)$ were higher in group I than group $\Pi$ and this finding was in agreement with Agrawl et al. (2009) who reported hypertriglyceridemia in $63.7 \%$, hypercholesterolemia in $50 \%-80 \%$, elevated LDL in $25 \%$ in patients with NAFLD [15]. Also, this finding was in agreement with [16] Nseir et al. (2011) who reported that dyslipidemia in patients with NAFLD is atherogenic in nature and it is characterized by increased levels of serum triglycerides and decreased levels of HDL cholesterol [16]. In this study, AST and ALT levels were elevated in NAFLD group more than control group and this finding was in agreement with Armstrong et al. (2012) who reported that NAFLD detected by ultrasonography was the most common cause of abnormal liver biochemistry [17]. In a study done by Debmalya et al. (2015) who concluded that NAFLD was significantly associated with higher ALT and GGT. Also, he reported that diabetic subjects with NAFLD had significantly higher ALT, AST and GGT and significantly lower AST: ALT ratio in comparison with diabetic subjects without NAFLD, but there was no significant difference in ALP levels [18]. In the present study, there was a relation between NAFLD patients and elevated blood sugar levels. Diabetes mellitus was observed in 15 patients in group I (21.4\%) and $0 \%$ in group $\Pi$. Mean levels of fasting blood sugar was higher in group I $(118.7 \pm 42.9)$ than group $\Pi(96.8 \pm 11.9)$. This matched the opinion of several authors as Leite et al., (2009) who stated that the prevalence of ultrasonographic NAFLD was $69.4 \%$ in 180 patients with T2DM [18]. Also, this was in agreement with Nascimbeni et al. (2013) who reported that NAFLD is strictly associated with metabolic risk factors especially obesity and type 2 diabetes mellitus (T2DM) [19]. In the current study, L-FABP levels were positively 
correlated with BMI $(\mathrm{r}=0.289, \mathrm{p}=0.015)$, AST $(\mathrm{r}=0.350, \mathrm{p}=0.003)$, ALT $(\mathrm{r}=$ $0.291, \mathrm{p}=0.015)$, total cholesterol $(\mathrm{r}=0.334, \mathrm{p}=0.005)$, triglycerides $(\mathrm{r}=0.244$, $\mathrm{p}=0.042)$, and LDL $(\mathrm{r}=0.301, \mathrm{p}=0.011)$. These findings matched with $\mathrm{Akbal}$ et al. (2014) who said in a similar study that L-FABP levels were positively correlated with BMI, glucose, AST, ALT and GGT levels [20]. The current study revealed statistically significant elevation in serum concentration of L-FABP levels in NAFLD group (group I) which was $(188.6 \pm 34.94)$ more than control group (group $\Pi$ ) which was $(137.7 \pm 13.05)$. This was in agreement with Akbal et al., (2014) who reported that serum L-FABP levels were elevated in NAFLD patients [20]. In the present study, Roc curve analysis of L-FABP as a diagnostic test of NAFLD suggested that at the cut off value $151.1 \mathrm{ng} / \mathrm{L}$ (that differentiate NAFLD from healthy group) the sensitivity, specificity, Positive and negative predictive values were $83.3 \%, 71.8 \%, 31.3 \%$ and $96.6 \%$ respectively with AUC was 0.834 , but at the cut off value $189.5 \mathrm{ng} / \mathrm{L}$ the sensitivity, specificity, positive and negative predictive values were $90 \%, 85 \%, 95.4 \%$ and $70.8 \%$ respectively with AUC was 0.950. So, in NAFLD pateints, increased serum levels of L-FABP increases the diagnostic accuracy(at the cut off value $151.1 \mathrm{ng} / \mathrm{L}$ diagnostic accuracy was $73.3 \%$ and at the cut off value $189.5 \mathrm{ng} / \mathrm{L}$ diagnostic accuracy was $88.9 \%$ ). This was in agreement with Akbal et al., (2014) who reported that to differentiate NAFLD from healthy controls, the cut-off value was $222.54 \mathrm{ng} / \mathrm{mL}$ for L-FABP ( $80 \%$ sensitivity and $80 \%$ specificity), positive and negative predictive values of L-FABP were $82 \%$ and $81 \%$, respectively and when the cut-off value was 284 ng/mL, L-FABP had $73 \%$ sensitivity and $100 \%$ specificity, Positive and negative predictive values for L-FABP were $100 \%$ and $79 \%$, respectively [20]. In the current study, there was a relation between levels of L-FABP in serum of NAFLD patients and grades of fatty liver by ultrasound as mean levels of L-FABP (177.6 $\pm 26.0)$ corresponded to grade I fatty liver, mean levels of $(189.4 \pm 29.2)$ corresponded to grade $\Pi$ fatty liver, mean levels of $(220.5 \pm 48.5)$ corresponded to grade $\amalg$ fatty liver and this was clinically and statistically significant $(\mathrm{p}<0.001)$. Also, there was a good positive correlation between grades of fatty liver by ultrasound and serum levels of L-FABP and this was statistically significant ( $\mathrm{p}=$ 0.002). As regards to concordance correlation coefficient between serum L-FABP and ultrasound in detection of NAFLD patients was $88.9 \%$ (by cohen kappa test $=0.70)$ and this was statistically significant $(\mathrm{p}<0.001 \mathrm{HS})$. This means that there is a good degree of agreement between U/S and L-FABP in detection of NAFLD patients. Also, the concordance correlation coefficient between serum L-FABP and ultrasound in detection of grade $\amalg$ of NAFLD was $72.8 \%$ (by cohen kappa test $=0.461$ ) and this was statistically significant $(\mathrm{p}<$ $0.001)$.

\section{Conclusion}

Liver fatty acid binding protein is a promising biomarker for early detection of liver injury in NAFLD when suspected by ultrasound and its levels correspond to the degree of fatty infiltration in liver tissue. 


\section{Acknowledgements}

The authors would like to thank the staff of Hepatology, Gastroenterology and Infectious Diseases Department in Benha University Hospital.

\section{Ethics Approval and Consent}

The Benha University Hospital Ethics Committee approved the study. All patients enrolled for the validation of this study gave a written informed consent.

\section{Conflicts of Interest}

The authors declare no conflicts of interest regarding the publication of this paper.

\section{References}

[1] Younossi, Z.M., Anstee, Q.M., Marietti, M., Hardy, T., Henry, T., Eslam, M., George, J. and Bugianesi. E. (2018) Global Burden of NAFLD and NASH: Trends, Predictions, Risk Factors and Prevention. Nature Reviews Gastroenterology \& Hepatology, 15, 11-20. https://doi.org/10.1038/nrgastro.2017.109

[2] McPherson, S., Hardy, T., Henderson, E., Burt, A.D., Day, C.P. and Anstee, Q.M. (2015) Evidence of NAFLD Progression from Steatosis to Fibrosing-Steatohepatitis Using Paired Biopsies: Implications for Prognosis and Clinical Management. Journal of Hepatology, 62, 1148-1155. https://doi.org/10.1016/j.jhep.2014.11.034

[3] Younossi, Z.M., Koenig, A.B., Abdelatif, D., Fazel, Y., Henry, L. and Wymer, M. (2016) Global Epidemiology of Nonalcoholic Fatty Liver Disease-Meta-Analytic Assessment of Prevalence, Incidence, and Outcomes. Hepatology, 64, 73-84.

https://doi.org/10.1002/hep.28431

[4] Higuchi, N., Kato, M., Tanaka, M., Miyazaki, M., Takao, S., Kohjima, M., et al. (2011) Effects of Insulin Resistance and Hepatic Lipid Accumulation on Hepatic mRNA Expression Levels of apoB, MTP and L-FABP in Non-Alcoholic Fatty Liver Disease. Experimental and Therapeutic Medicine, 2, 1077-1081.

https://doi.org/10.3892/etm.2011.328

[5] Leite, N.C., Salles, G.F., Araujo, A.L., Villela-Nogueira, C.A. and Cardoso, C.R. (2009) Prevalence and Associated Factors of Non-Alcoholic Fatty Liver Disease in Patients with Type-2 Diabetes Mellitus. Liver International, 29, 113-119. https://doi.org/10.1111/j.1478-3231.2008.01718.x

[6] Kim, Y.C., Cho, Y.K., Lee, W.Y., Kim, H.J., Park, J.H., Park, D.I., et al. (2011) Serum Adipocyte-Specific Fatty Acid-Binding Protein Is Associated with Nonalcoholic Fatty Liver Disease in Apparently Healthy Subjects. The Journal of Nutritional Biochemistry, 22, 289-292. https://doi.org/10.1016/j.jnutbio.2010.02.007

[7] Pelsers, M.M., Morovat, A., Alexander, G.J., Hermens, W., Trull, A.K., Glatz, J.F., et al. (2002) Liver Fatty Acidbinding Protein as a Sensitive Serum Marker of Acute Hepatocellular Damage in Liver Transplant Recipients. Clinical Chemistry, 48, 2055-2057.

[8] Ishimitsu, T., Ohta, S., Saito, M., Teranishi, M., Inada, H., Yoshii, M., et al. (2005) Urinary Excretion of Liver Fatty Acid-Binding protein in Health-Check Participants. Clinical and Experimental Nephrology, 9, 34-39.

https://doi.org/10.1007/s10157-004-0331-x

[9] Pelsers, M., Hermens, W. and Glatz, J.F. (2005) Fatty Acid-Binding Proteins as 
Plasma Markers of Tissue Injury. Clinica Chimica Acta, 352, 15-35. https://doi.org/10.1016/j.cccn.2004.09.001

[10] Haunerland, N.H. and Spener, F. (2004) Fatty Acid-Binding Proteins-Insights from Genetic Manipulations. Progress in Lipid Research, 43, 328-349. https://doi.org/10.1016/j.plipres.2004.05.001

[11] Saadeh, S., Younossi, Z.M., Remer, E.M., Gramlich, T., Ong, J.P., Hurley, M., et al. (2002) The Utility of Radiological Imaging in Nonalcoholic Fatty Liver Disease. Gastroenterology, 123, 745-750. https://doi.org/10.1053/gast.2002.35354

[12] Sayiner, M., Koenig, A., Henry, L. and Younossi, Z. (2016) Epidemiology of Nonalcoholic Fatty Liver Disease and Nonalcoholic Steatohepatitis in the United States and the Rest of the World. Clinics in Liver Disease, 20, 205-214.

https://doi.org/10.1016/j.cld.2015.10.001

[13] Niriella, M.A., Pathmeswaran, A., De Silva, S.T., Kasturiratna, A., Perera, R., Subasinghe, C.E., et al. (2017) Incidence and Risk Factors for Non-Alcoholic Fatty Liver Disease: A 7-Year Follow Up. Liver International, 37, 1715-1722. https://doi.org/10.1111/liv.13478

[14] Williams, C.D., Stengel, J., Asike, M.I., Torres, D.M., Shaw, J., Contreras, M., et al. (2011) Prevalence of Nonalcoholic Fatty Liver Disease and Nonalcoholic Steatohepatitis among a Largely Middle-Aged Population Utilizing Ultrasound and Liver Biopsy: A Prospective Study. Gastroenterology, 140, 124-131. https://doi.org/10.1053/j.gastro.2010.09.038

[15] Agrawal, R., Mishra, S., Dixit, V.K. and Rai, S. (2009) Association of Non-Alcoholic Fatty Liver Disorder with Obesity. Indian Journal of Preventive \& Social Medicine, 40, 126-129.

[16] Nseir, W., Shalata, A., Marmor, A. and Assy, N. (2011) Mechanisms Linking Nonalcoholic Fatty Liver Disease with Coronary Artery Disease. Digestive Diseases and Sciences, 56, 3439-3449. https://doi.org/10.1007/s10620-011-1767-y

[17] Armstrong, M.J., Houlihan, D.D., Bentham, L., Shaw, J.C., Cramb, R., Olliff, S., et al. (2012) Presence and Severity of Non-Alcoholic Fatty Liver Disease in a Large Prospective Primary Care Cohort. Journal of Hepatology, 56, 234-240. https://doi.org/10.1016/j.jhep.2011.03.020

[18] Debmalya, S., Pradip, M., Moutusi, R., Sujoy, G., Satinath, M. and Subhankar, C. (2015) Indian Journal of Endocrinology Metabolism, 19, 597-601.

[19] Nascimbeni, F., Pais, R., Bellentani, S., Day, C.P., Ratziu, V., Loria, P., et al. (2013) From NAFLD in Clinical Practice to Answers from Guidelines. Journal of Hepatology, 59, 859-871. https://doi.org/10.1016/j.jhep.2013.05.044

[20] Akbal, E., Koçak, E., Akyürek, O., Köklü, S., Batgi, H. and Senes, M. (2014) Liver Fatty Acid-Binding Protein as a Diagnostic Marker for Non-Alcoholic Fatty Liver Disease. Wiener Klinische Wochenschrift, 128, 7-8.

https://doi.org/10.1007/s00508-014-0680-8 